\title{
Weather-Based Fungicide Spray Programs for Control of Two Foliar Diseases on Carrot Cultivars Differing in Susceptibility
}

\author{
P. M. Rogers, Graduate Research Assistant, and W. R. Stevenson, Professor and Extension Plant Pathologist, De- \\ partment of Plant Pathology, University of Wisconsin-Madison, Madison 53706
}

\begin{abstract}
Rogers, P. M., and Stevenson, W. R. 2006. Weather-based fungicide spray programs for control of two foliar diseases on carrot cultivars differing in susceptibility. Plant Dis. 90:358-364.

Foliar diseases of carrot caused by Alternaria dauci and Cercospora carotae occur every year in Wisconsin, requiring repeated foliar fungicide applications to minimize defoliation and yield reduction. Improved timing of fungicide applications combined with the use of disease resistant cultivars offer growers a means to improve disease control with fewer fungicide inputs compared with the current strategy of weekly fungicide applications to a susceptible cultivar. Field experiments in 2002 to 2004 examined fungicide application schedules indicated by a disease forecasting model that calculated the duration of environmental conditions favorable for $A$. dauci and $C$. carotae (adaptation of TOM-CAST) on two carrot cultivars differing in susceptibility to these foliar diseases. All fungicide programs were initiated at a $1 \%$ disease severity threshold determined by scouting. Intervals for weather-based spray programs were based on in-canopy leaf wetness and temperature data. Fungicide sprays were applied according to 15 and 20 disease severity value (DSV) application thresholds, and were compared with a weekly spray program and an untreated control. Results of this trial demonstrated that fungicide sprays made according to weather data may reduce fungicide inputs in most years compared with current industrystandard, calendar-based spray programs. Host susceptibility affected the efficacy of weatherbased spray programs, resulting in longer spray intervals and fewer fungicide applications on the resistant cultivar Bolero when compared with the susceptible cultivar Fontana. Fungicide spray programs based on TOM-CAST diminished fungicide inputs by 30 to $50 \%$, compared with the weekly spray program, by lengthening intervals between applications without compromising disease control or root yield.
\end{abstract}

Alternaria dauci (Kuhn) Groves \& Skolko and Cercospora carotae (Pass.) Solheim cause substantial and recurrent yield losses in commercial carrot (Daucus carota var. sativa L.) crops across North America $(1,7,14,16,26,27,33)$. Alternaria leaf blight (ALB) and Cercospora leaf spot (CLS) adversely impact production of processing carrots in Wisconsin, requiring 4 to 12 (average 7) foliar fungicide applications each year to suppress these diseases (unpublished grower survey). ALB and CLS damage carrots by blighting and eventually killing foliage during persistent environmental conditions with extended periods of leaf wetness $(>4 \mathrm{~h})$ and mild temperatures $\left(14\right.$ to $\left.28^{\circ} \mathrm{C}\right)(5,14,26,31,32)$. Diseased plants lose leaves in repeated cycles, disrupting photosynthesis and draining resources that may otherwise be stored as root yield $(1,5,7,10,20,33)$. Weakened and defoliated plants also impair commercial harvesting, because healthy leaves and strong petioles are es-

Corresponding author: P. M. Rogers

E-mail: pmr@plantpath.wisc.edu

Accepted for publication 26 October 2005.

DOI: 10.1094/PD-90-0358

(C) 2006 The American Phytopathological Society sential for a mechanical harvester to grip the foliage and lift roots from the field. When carrot foliage is severely blighted, unharvested roots remaining in the ground contribute to additional yield losses (26).

ALB and CLS defoliate susceptible commercial carrot cultivars each year in Wisconsin, resulting in reduced vigor, canopy decline, and variable yield loss. Field trials in Wisconsin have demonstrated 20 to $30 \%$ reductions in root yield when comparing plots receiving no fungicide to a weekly application program (19). Similar studies in Florida, North Carolina, New York, and Michigan have shown 20 to $80 \%$ yield loss when plants were left untreated $(4,33,34 ;$ G. S. Abawi, personal communication). Consequently, carrot growers must protect crop yields by spraying fungicides repeatedly from July through September.

Applying fungicides according to periods favorable for disease development has improved control of early blight (Alternaria solani) on tomato and potato, while reducing the number of fungicide sprays required for control compared with calendar-based spray schedules $(13,24,25,29)$. Forecasting systems developed for early blight, FAST (Forecasting Alternaria solani on Tomato) (24) and the modified version, TOM-CAST (Tomato disease forecaster) (25), indicate leaf wetness and temperature are critical environmental factors influencing infection, sporulation, and disease development. The FAST and TOM-CAST models use in-field or incanopy environmental monitoring equipment to measure microclimate conditions that directly influence foliar disease development $(24,25)$. For TOM-CAST, disease severity values (DSV) are calculated from leaf wetness and temperature data collected within the canopy, summed for each calendar day, and accumulated to a treatment threshold (25). Research on potatoes using Blitecast, a late blight forecasting program, has demonstrated comparable control of foliar late blight caused by Phytophthora infestans with fewer chemical applications than a calendar schedule $(9,10,15,21)$.

Evidence from field and controlled environment experiments on carrot suggests leaf wetness and temperature are two essential parameters influencing $A$. dauci and C. carotae growth, sporulation, and disease development $(1,5,14,31,32,34)$. Environmental conditions favorable for growth, sporulation, and dispersal for A. solani on tomato or potato are comparable to conditions favorable for growth, sporulation, and dispersal of A. dauci and C. carotae on carrot foliage $\left(14\right.$ to $28^{\circ} \mathrm{C}$, periods of leaf wetness and humidity $>90 \%)(5,6,14$, 22,24,31,32). A recent study in Michigan examined the TOM-CAST model on carrots to reduce fungicide sprays compared with a 10-week, 7-day calendar schedule. The authors also determined effective DSV thresholds $(10,15$, or 20 DSV) for fungicide applications and indicated similar disease control could be achieved with fewer sprays using TOM-CAST on a susceptible carrot cultivar compared with a weekly calendar schedule (4). Monitoring carrot canopy conditions, including leaf wetness, rainfall, relative humidity, and temperature, is expected to contribute to more accurate timing of fungicide applications compared with a calendar approach, likely improving control efficacy. Using the TOM-CAST model to determine fungicide application intervals based on accumulated DSV may reduce the number of pesticide sprays and cost associated with disease management in the production of processing carrots.

Carrot cultivars differ substantially in their susceptibility to ALB and CLS $(3,8,18,26,28)$. Differences in the disease reactions of carrot cultivars and breeding 
lines have been documented through field trials in Israel, Europe, and North America $(3,18,23,26,28)$. The majority of cultivars acceptable to Wisconsin carrot processors are highly susceptible to both ALB and CLS. Carrot cultivars have been traditionally selected based on horticultural or processing characteristics, which often supersede utilization of more resistant materials. However, the cultivar Bolero (Vilmorin Seed Co., LaMenitre, France) is a resistant line currently available to Wisconsin growers that routinely shows fewer lesions per plant and minimal impact of disease on carrot yield compared with standard susceptible cultivars $(18,28)$. Host resistance has been shown to play a key role in the fungicide program required to manage foliar diseases in other vegetable crops $(9-12,15,30)$. This suggests that host resistance might be factored into carrot fungicide programs and that less fungicide may be required for disease control on resistant lines such as Bolero, compared with susceptible cultivars.

Fungicide applications are typically initiated when plants are $20 \mathrm{~cm}$ tall and continue on a calendar schedule ( 7 to 10 days) until harvest in most Wisconsin commercial fields (unpublished grower survey). However, symptoms of ALB and CLS are rarely observed in the early stages of plant development, prior to canopy closure (e.g., leaflets touching between rows, $>20 \mathrm{~cm}$ tall). Field experiments in Canada have shown effective control of ALB and CLS when fungicide applications were delayed until disease recognition or until a specified disease incidence threshold was reached $(1,14,20)$. In addition to environmental influence on disease development, young foliage is believed to be somewhat less susceptible to ALB than mature leaves (26,32). For these reasons, delaying fungicide sprays beyond the $20-\mathrm{cm}$ developmental stage until first symptom detection may reduce the number of early season fungicide applications for control of ALB and CLS.

Grower reliance on calendar fungicide applications is in part related to the limited integrated pest management (IPM) research aimed at ALB and CLS control. A disease management program for carrots that incorporates a forecasting model, host resistance, field scouting, and disease monitoring is likely to reduce the number of fungicide inputs necessary for control. The objectives of this research were (i) to examine the use of TOM-CAST to forecast ALB and CLS development and reduce the number of fungicide applications needed for effective disease control, and (ii) to assess the impact of using cultivar resistance and disease monitoring on the management of these two foliar diseases with weather-based fungicide spray programs.

\section{MATERIALS AND METHODS}

Experimental design. Field trials were established at the Hancock Agricultural Research Station in central Wisconsin during 2002 to 2004 . Research plots were located $<2 \mathrm{~km}$ from several commercial carrot fields which provided natural sources of $A$. dauci and $C$. carotae inoculum for disease development each year. The experiments incorporated typical commercial production practices including planting of cultivars in continuous blocks, commercial seeding rates, commercial plant densities, weekly field scouting, and nontarget pest management practices. The efficacy of fungicide treatment programs was evaluated by examining disease severity, seasonal disease progress, and impact of treatment on root yield and carrot value (e.g., root quality, shape, and diameter).

Two cultivars were selected based on their susceptibility to ALB and CLS observed in previous field experiments $(18,28)$ : Fontana (Bejo Zaden, Warmenhuizen, The Netherlands; a dicing type carrot susceptible to ALB and CLS) and Bolero (a slicing type carrot resistant to ALB and CLS). Seeds were machine planted using a standard commercial vacuum planter (Singular 785, Stanhay Precision Planters, Salinas, CA). Bolero seeds were planted at a rate of 222,585 seeds per ha, and Fontana seeds were planted at 101,175 seeds per ha. Final plant densities were approximately 116 plants per $\mathrm{m}^{2}$ for Bolero and 54 plants per $\mathrm{m}^{2}$ for Fontana, comparable to commercial crop densities for each carrot type. Oat seed was broadcast during bed shaping to provide a cover crop for early-season wind protection. A description of plot details, cultivars, and time at which $1 \%$ disease severity was observed is shown in Table 1.
Experiments were laid out in a randomized complete block, with each cultivar planted in a block, and fungicide spray programs were randomized within each of four replicates. Experimental plots consisted of a $1.83-\mathrm{m}$-wide raised bed with three 6.71-m-long carrot rows planted 0.61 $\mathrm{m}$ apart. Plots were separated on either end by a $3.66-\mathrm{m}$ alley to facilitate herbicide and insecticide applications. Soil type was Plainfield sand with pH 6.8 in 2002 and 2003 and pH 6.9 in 2004. Potash (0-0-61) fertilizer was broadcast at $280.2 \mathrm{~kg} / \mathrm{ha}$ during bed shaping on 19 April 2002, 18 April 2003, and 26 April 2004 as a preemergence amendment to aid in carrot emergence. Additional fertilizer was applied when plants reached four true leaves as a sidedress consisting of $\mathrm{NH}_{3} \mathrm{SO}_{4}(88.8$ $\mathrm{kg} / \mathrm{ha}$ ), mono-ammonium phosphate (11$52-0 ; 44.4 \mathrm{~kg} / \mathrm{ha}$ ), potassium-magnesium $(2-2-22 ; 177.6 \mathrm{~kg})$, and boron $(0.5 ; 177.6$ $\mathrm{kg})$. Nitrogen was applied through overhead pivot or linear irrigation (28\% UAN, $33.6 \mathrm{~kg} \mathrm{~N} / \mathrm{ha}$ ) in three applications from late July through early August in each year. Herbicide and insecticide applications were similar to typical grower practices and in accordance with labeled rates.

Irrigation was applied through overhead pivot (2002 and 2004) or linear (2003) irrigation in accordance with typical commercial practices. Irrigation was applied to all plots consisting of $38 \mathrm{~cm}$ in 21 applications from May to October of 2002, $33 \mathrm{~cm}$ in 26 applications June to October of 2003, and $35 \mathrm{~cm}$ in 28 applications from May to October of 2004.

Disease forecasting model. Based on previous findings, the TOM-CAST model appeared to be an appropriate forecasting tool to predict ALB and CLS occurrence on carrot and to indicate when fungicide applications were most effective (4). Spray intervals for the weather-based fungicide spray programs utilized the TOM-CAST DSV model $(24,25)$. Leaf wetness and temperature data were collected, stored, and analyzed using an in-canopy Watchdog Datalogger 450 with Specware 6.02 software (Spectrum Technologies Inc., Plainfield, IL) located in each cultivar. Weather data were transferred to a laptop computer and analyzed every 2 days. DSV were calculated and summed independently for each spray program.

Table 1. Details of carrot cultivars, crop growth stages, and date of initial foliar disease observation in field trials evaluating fungicide spray programs for control of Alternaria leaf blight and Cercospora leaf spot

\begin{tabular}{lcccccc}
\hline & & & & \multicolumn{2}{c}{ 1\% Disease severity $^{\mathbf{a}}$} \\
\cline { 5 - 7 } Year & Cultivar & Planting date & Emergence date & Harvest date & Date & DAP \\
\hline 2002 & Bolero & 8 May & 20 May & 2 October & 4 August \\
2002 & Fontana & 8 May & 22 May & 3 October & 23 July & 76 \\
2003 & Bolero & 6 May & 22 May & 30 September & 9 August & 95 \\
2003 & Fontana & 6 May & 25 May & 29 September & 21 July & 76 \\
2004 & Bolero & 11 May & 25 May & 5 October & 8 August & 26 July \\
2004 & Fontana & 11 May & 27 May & 5 October & 76 \\
\hline
\end{tabular}

a Time, expressed as calendar date and days after planting (DAP), when symptoms were observed at the threshold level of $1 \%$ disease severity for Alternaria leaf blight and/or Cercospora leaf spot on each cultivar. 
Following carrot seedling emergence, all plots were scouted weekly for the presence of ALB and CLS symptoms. Timing of developmental stages and initial disease observations are listed in Table 1. Foliar fungicide applications were initiated separately for Bolero and Fontana upon observation of $1 \%$ disease severity in plots of each cultivar. Disease severity at the $1 \%$ age within each cultivar and comparing leaf samples with the disease damage index for carrot leaves established by Strandberg (32). The accumulation of DSV began after the first fungicide spray for each cultivar. DSV thresholds used in this study were 15 DSV (conservative) and 20 DSV (liberal) application intervals. When the appropriate DSV threshold was reached for each cultivar, a fungicide application was made and the DSV counter was reset to zero. Subsequent sprays were applied each time the specified DSV threshold was reached.

Fungicide spray programs. Schedules of fungicide spray programs are summarized in Table 2. The alternation of chlorothalonil followed by azoxystrobin has proven highly effective for control of ALB and CLS in previous field experiments (18). The protectant fungicide Bravo Ultrex $82.5 \%$ WDG (chlorothalonil, Syngenta Corp., Greensboro, NC) was applied at a rate of $1.57 \mathrm{~kg} / \mathrm{ha}$ and alternated with Quadris 2.08 SC (azoxystrobin, Syngenta Corp.), a flowable broad-spectrum fungicide applied at a rate of $672.3 \mathrm{ml} / \mathrm{ha}$.

Treatments consisted of an untreated control, a weekly foliar fungicide program, and two weather-based fungicide spray programs (Table 2). Fungicides were applied with a backpack attached to a $1.07-\mathrm{m}$ boom equipped with 4 XR11003VS nozzles (Spraying Systems Co., Wheaton, IL) pressurized with $\mathrm{CO}_{2}$. All fungicide treatments were applied in a volume equivalent to 327.4 liters of water per ha at $276 \mathrm{kPa}$. Fungicides were applied during morning hours after dew had evaporated and when level was determined by monitoring foli-

wind speeds were $<2.2 \mathrm{~m} / \mathrm{s}$ to prevent drift onto adjacent plots.

Toxicity scores. Each fungicide application used in this study was entered into the Realtoolbox (SureHarvest Inc., CA) computer software. Toxicity values were calculated for each fungicide applied based on fungicide chemistry, rate of product applied per acre, and toxicity assessment protocols developed for pesticides used on potatoes (2). Toxicity units provide an overall measure of pesticide toxicity incorporating four component indices: acute mammalian toxicity, chronic mammalian toxicity, ecological impacts, and impacts on beneficial organisms and IPM systems (2).

Disease assessment. Disease severity was rated every 7 to 10 days on four 0.9 $\mathrm{m}$-long sections (equivalent to 50 plants of Fontana and 110 of Bolero) in the center row in each plot. Ratings began after observation of $1 \%$ disease severity and continued until 1 week prior to harvest. Although symptoms of each disease were distinguishable, no attempt was made to separate symptoms of ALB and CLS because of the similarity and close proximity of foliar symptoms. Disease symptom severity was estimated according to the Horsfall-Barratt rating system (0 to 11), and ratings were converted to percent disease severity (17). Disease severity means were used to calculate the relative area under the disease progress curve (RAUDPC). Analyses of variance (ANOVA) were conducted on the disease severity values and RAUDPC using PROC GLM in UNIX SAS version 8.0 (SAS Institute Inc., Cary, NC). Disease severity (\%) and RAUDPC means were compared using Fisher's least significant difference (LSD). Treatments were analyzed within and across both cultivars, as appropriate.

Harvest data collection. Samples of experimental plots were harvested when roots achieved full maturity. Two 1.52-mlong sections of the center test row of each plot were hand-dug from each plot on 2

Table 2. Foliar fungicide spray programs evaluated for control of Alternaria leaf blight and Cercospora leaf spot on carrot

\begin{tabular}{lccccc}
\hline & & \multirow{2}{*}{$\begin{array}{c}\text { Treatment } \\
\text { Cultivar }\end{array}$} & & \multicolumn{2}{c}{ Number of applications (total a.i. $\mathbf{k g} / \mathbf{h a})^{\mathbf{a}}$} \\
\cline { 5 - 6 } & Treatment $^{\mathbf{c}}$ & schedule & $\mathbf{2 0 0 2}$ & $\mathbf{2 0 0 3}$ & $\mathbf{2 0 0 4}$ \\
\hline Bolero & Untreated & None & 0 & 0 & 0 \\
& BU/Q & 20 DSV & $3(2.76)$ & $2(1.47)$ & $2(1.47)$ \\
& BU/Q & 15 DSV & $4(2.94)$ & $3(2.76)$ & $3(2.76)$ \\
\multirow{4}{*}{ Fontana } & BU/Q & Weekly & $7(5.71)$ & $7(5.71)$ & $7(5.71)$ \\
& Untreated & None & 0 & 0 & 0 \\
& BU/Q & 20 DSV & $4(2.94)$ & $3(2.76)$ & $3(2.76)$ \\
& BU/Q & 15 DSV & $5(3.78)$ & $4(2.94)$ & $4(2.94)$ \\
& BU/Q & Weekly & $8(5.92)$ & $8(5.92)$ & $8(5.92)$ \\
\hline
\end{tabular}

${ }^{a}$ Total number of fungicide applications and total active ingredient applied for a season-long program for each spray program.

${ }^{\mathrm{b}}$ Bolero is resistant and Fontana is highly susceptible to Alternaria leaf blight (ALB) and Cercospora leaf spot (CLS).

${ }^{c}$ Fungicides applied for crop protection were Bravo Ultrex 82.5 WDG (BU) (chlorothalonil) applied at $1.31 \mathrm{~kg}$ a.i./ha and Quadris $2.08 \mathrm{SC}(\mathrm{Q})$ (azoxystrobin) applied at $0.17 \mathrm{~kg}$ a.i./ha. Fungicides were alternated in each spray program. and 3 October 2002, 29 September 2003, and 5 October 2004, and weighed to estimate total yield (Table 3 ). The value of processed carrots in Wisconsin is determined by yield as measured by root diameter and root quality (e.g., color, shape, or flavor). Yield values were calculated for each treatment based on typical processing contracts. Harvested roots were hand graded into five size classes based on diameter and culls (e.g., misshapen or rotten). Size class data were then grouped according to processing standards for slicing and dicing type carrots. Minimum size accepted for dicing carrot types is $3.2 \mathrm{~cm}$, and discard class includes culls and carrots below the minimum diameter. Dicing base price per ton is: $>90.1 \%$ over $5.1 \mathrm{~cm}$ diameter $=\$ 44.60 ; 80.1$ to $90 \%>5.1 \mathrm{~cm}=$ $\$ 41.80 ; 70.1$ to $80 \%>5.1 \mathrm{~cm}=\$ 38.15$; 60.1 to $70 \%>5.1 \mathrm{~cm}=\$ 36.60 ; 50.1$ to $60 \%>5.1 \mathrm{~cm}=\$ 35.40$; and $<50 \%>5.1$ $\mathrm{cm}=\$ 34.20$. Minimum size accepted for slicing type carrots is $1.9 \mathrm{~cm}$ diameter; discard class includes culls and carrots below the minimum diameter. Slicing base price per ton is: $<10 \%$ over $4.5 \mathrm{~cm}$ diameter $=\$ 54.70 ; 10$ to $19 \%>4.5 \mathrm{~cm}=$ $\$ 53.90 ; 20$ to $29 \%>4.5 \mathrm{~cm}=\$ 52.40 ; 30$ to $39 \%>4.5 \mathrm{~cm}=\$ 49.40 ; 40$ to $49 \%>$ $4.5 \mathrm{~cm}=\$ 46.45$; and $>49 \%>4.5 \mathrm{~cm}=$ $\$ 43.60$. An ANOVA was conducted on yield and calculated crop value using PROC GLM in SAS, and treatments were compared using Fisher's least significant difference.

\section{RESULTS}

Disease scouting and fungicide spray program initiation. Plots were monitored every 7 days for the presence of ALB and CLS from emergence to first observation of symptoms in 2002 to 2004. Symptoms of ALB and CLS first appeared in Fontana plots on 23 July 2002, 21 July 2003, and 26 July 2004, 76 days after planting (DAP) for all 3 years (Table 1). The first symptoms of ALB or CLS were recognized on Bolero 12, 19, and 13 days later, respectively, than on Fontana (Table 1). Delaying the initial fungicide application until disease was detected at threshold levels resulted in at least one fewer fungicide application on the resistant cultivar Bolero compared with Fontana, in each year of the study (Table 2).

Disease assessments. The efficacy of fungicide spray programs to control foliar diseases was assessed by comparing disease severity on each rating date (nine in 2002 and 2004; eight in 2003), overall disease progress (RAUDPC), and the effect of treatment on carrot yield (Fig. 1 and Table 3). Significant differences in control of ALB and CLS were observed among spray programs on Bolero and Fontana. Similar results were achieved in each year of the study, with the greatest symptom expression and disease damage observed in 2002 compared with 2003 and 2004. 
Symptoms of ALB were more frequent in 2002, CLS was more prevalent in 2003, and both diseases were observed at similar levels in 2004. In each field season, disease symptoms advanced more quickly in treatments on Fontana plots than on Bolero plots, and carrot yield was reduced to some extent for both cultivars in the untreated control compared with plots sprayed with chlorothalonil and azoxystrobin. Observations on each cultivar-spray program combination are summarized below.

Bolero. Disease severity and RAUDPC for all spray programs on Bolero were significantly less than that observed on Fontana treatments with the exception of the Fontana weekly program (Table 3 and Fig. 1). Disease severity remained $<20 \%$ by the final rating in all 3 years on untreated Bolero (Fig. 1). All fungicide spray programs on Bolero provided significantly better disease control than that obtained with the resistant cultivar alone; however, statistical differences were not noted among fungicide treatments in 2002 or 2003 (Fig. 1, Table 3). The 20 DSV fungicide schedule limited symptom severity to $9.1 \%$ disease severity in $2002,8.8 \%$ in 2003 , and $5.5 \%$ in 2004 by the final rating date. The 15 DSV schedule provided comparable disease control, limiting disease severity to $6.7 \%$ disease severity in 2002 , $10.5 \%$ in 2003 , and $4.7 \%$ in 2004 by the final rating date. Weekly fungicide applications (four additional sprays in 2002 and five additional sprays in 2003) did not improve control statistically compared with plots treated at 20 DSV intervals; however, in 2004 the weekly program produced an RAUDPC value significantly lower than the 20 DSV spray program (Table 3 ).
Total yield and crop value in Bolero plots was largely unaffected by the fungicide spray program used in this experiment (Table 3). Yield in the untreated control was statistically lower than yield in plots treated weekly in 2003, but not in 2002 or 2004. The 20 DSV TOM-CAST spray program provided the highest yield (78.9 $\mathrm{t} / \mathrm{ha}$ in 2002) of all Bolero treatments in 2002, and yields in the 20 DSV treatment were not significantly different from the weekly or 15 DSV spray programs in 2003 or 2004. These data suggest Bolero could be grown using the 20 DSV TOM-CAST program in most years, requiring fewer fungicide sprays than the traditional weekly calendar schedule while achieving adequate disease control.

Fontana. Disease severity in the Fontana untreated control exceeded $50 \%$ at 123 DAP and progressed to $83 \%$ by harvest, displaying an RAUDPC value of 0.278 . Under lower disease pressure in 2003 and 2004, disease severity in untreated Fontana plots exceeded $65 \%$ by 132 DAP and $45 \%$ by 135 DAP, respectively, with RAUDPC values of 0.281 and 0.175 , respectively. By harvest in each year of the study, untreated plants were moderately to severely defoliated, stunted, and petioles had become brittle. Fungicide sprays applied on a weekly schedule (eight sprays) provided the most effective control of foliar diseases in each year of the study on Fontana (Table 3 ). The weekly spray program was not significantly more effective than the 15 DSV schedule in 2003 or 2004 as measured by RAUDPC (Table 3). Furthermore, the weekly schedule did not significantly reduce disease severity on any rating date compared with the 15 DSV spray schedule over all 3 years (Fig. 1). Severity of foliar diseases was $23 \%$ by the final rating in 2002 (five sprays), 15\% in 2003 (four sprays), and $8 \%$ in 2004 (four sprays) under the 15 DSV treatment program. Use of a 15 DSV threshold reduced the number of fungicide applications by three sprays in 2002 and four sprays in 2003 and 2004, compared with the weekly program (Table 2). In contrast, the 20 DSV TOM-CAST spray program on Fontana provided less effective control of ALB and CLS and lower yields compared with the weekly program in 2002 and 2003, but not in 2004. Disease severity in the 20 DSV Fontana plots reached $40 \%$ in $2002,25 \%$ in 2003 , and $12 \%$ in 2004 , which was less than in the unsprayed control plots but greater than plots receiving fungicide according to a 15 DSV or weekly spray program.

Yield in plots treated with a weekly or 15 DSV spray program was significantly greater than that of the untreated control in each year of the study (Table 3). Total marketable yield in the untreated plots was 15 to $25 \%$ less than in fungicide-treated plots in all 3 years. Yield was greatest in plots treated at 15 DSV intervals in 2002 and 2003 (100.9 t/ha in 2002 and 106.7 $\mathrm{t} / \mathrm{ha}$ in 2003), but not in 2004. Yield in plots treated weekly with fungicide was not significantly different from yield in plots treated at 20 DSV intervals in each year. Statistically, no additional benefit in total yield was measured on Fontana with the addition of three or four fungicide applications in association with the weekly spray program compared with the $15 \mathrm{DSV}$ spray program.

Fungicide spray programs based on infield weather data indicated fewer sprays

Table 3. Relative area under the disease progress curve, total yield, and gross value of harvested carrots for fungicide applications made weekly, or according to 15 or 20 disease severity value intervals, for control of Alternaria leaf blight and Cercospora leaf spot on carrot ${ }^{\mathrm{a}}$

\begin{tabular}{|c|c|c|c|c|c|c|c|c|c|c|}
\hline \multirow{2}{*}{\multicolumn{2}{|c|}{$\begin{array}{l}\text { Cultivar and fungicide } \\
\text { spray program }\end{array}$}} & \multicolumn{3}{|c|}{ RAUDPC $^{\mathbf{b}}$} & \multicolumn{3}{|c|}{ Total yield (t/ha) ${ }^{\mathrm{c}}$} & \multicolumn{3}{|c|}{$\begin{array}{c}\text { Gross value of yield } \\
\text { based on carrot type }(\$)^{d}\end{array}$} \\
\hline & & \multirow{2}{*}{$\begin{array}{r}2002 \\
0.066\end{array}$} & \multirow{2}{*}{$\begin{array}{c}\mathbf{2 0 0 3} \\
0.051\end{array}$} & \multirow{2}{*}{$\begin{array}{r}\mathbf{2 0 0 4} \\
0.044\end{array}$} & \multirow{2}{*}{$\frac{2002}{69.8}$} & \multirow{2}{*}{$\begin{array}{c}2003 \\
61.9\end{array}$} & \multirow{2}{*}{$\begin{array}{c}2004 \\
75.3\end{array}$} & \multirow{2}{*}{$\frac{\mathbf{2 0 0 2}}{2,801.8}$} & \multirow{2}{*}{$\begin{array}{c}\mathbf{2 0 0 3} \\
2,529.9\end{array}$} & \multirow{2}{*}{\begin{tabular}{c|}
$\mathbf{2 0 0 4}$ \\
$2,399.3$
\end{tabular}} \\
\hline Bolero & Untreated & & & & & & & & & \\
\hline & 20 DSV & 0.039 & 0.035 & 0.028 & 78.9 & 67.2 & 75.6 & $3,035.9$ & $2,563.2$ & $2,733.9$ \\
\hline & $15 \mathrm{DSV}$ & 0.029 & 0.039 & 0.023 & 76.0 & 71.5 & 78.5 & $2,919.1$ & $2,959.0$ & $2,575.3$ \\
\hline & Weekly & 0.033 & 0.036 & 0.018 & 77.4 & 75.7 & 81.8 & $3,001.2$ & $3,198.9$ & $3,220.4$ \\
\hline & $P>F$ & $<0.01$ & 0.01 & $<0.01$ & 0.06 & 0.03 & 0.73 & 0.30 & 0.14 & 0.37 \\
\hline & LSD & 0.011 & 0.009 & 0.008 & 7.0 & 9.0 & NS & NS & NS & NS \\
\hline Fontana & Untreated & 0.278 & 0.281 & 0.175 & 68.9 & 63.7 & 74.0 & $2,060.1$ & $1,889.1$ & $1,595.3$ \\
\hline & 20 DSV & 0.114 & 0.096 & 0.055 & 83.7 & 89.2 & 89.2 & $2,471.8$ & $2,428.5$ & $2,300.9$ \\
\hline & $15 \mathrm{DSV}$ & 0.079 & 0.074 & 0.052 & 100.9 & 106.7 & 87.7 & $3,146.5$ & $2,845.1$ & $1,881.6$ \\
\hline & Weekly & 0.055 & 0.062 & 0.040 & 87.2 & 94.2 & 92.1 & $2,687.4$ & $2,888.6$ & $1,732.1$ \\
\hline & $P>F$ & $<0.01$ & $<0.01$ & $<0.01$ & 0.02 & $<0.01$ & 0.01 & 0.02 & 0.02 & 0.62 \\
\hline & LSD & 0.013 & 0.014 & 0.039 & 17.7 & 11.9 & 11.7 & 631.4 & 611.9 & NS \\
\hline \multicolumn{11}{|c|}{ Analysis of spray programs across both cultivars } \\
\hline & $P>F$ & $<0.01$ & $<0.01$ & $<0.01$ & $<0.01$ & $<0.01$ & $<0.01$ & $<0.01$ & 0.01 & 0.45 \\
\hline & LSD & 0.012 & 0.011 & 0.025 & 5.7 & 5.3 & 5.1 & 195.8 & 303.2 & NS \\
\hline
\end{tabular}

${ }^{\text {a }}$ Disease severity values (DSV) were calculated according to the TOM-CAST disease forecasting model based upon temperature and leaf wetness data collected within the carrot canopy.

${ }^{\mathrm{b}}$ Relative area under the disease progress curve (RAUDPC). Disease severity (\%) for each date was plotted on a graph and the area under the curve was calculated for each spray program.

${ }^{\mathrm{c}}$ Carrots were graded into five size classes and culls (misshapen or rotted). The size classes were then grouped appropriately to standards for dicing or slicing carrots.

d Values are calculated per hectare based on 2003 (dicer) or 2002 (slicer) processing contracts for uncrowned carrots. Gross value of yield was calculated using slicing contract data for Bolero and dicing contract data for Fontana. 
than the weekly program, regardless of cultivar. The number of fungicide applications was reduced by three to five on both the susceptible and resistant cultivar. Total yield in the 15 DSV spray program on Fontana and the 20 DSV spray program on Bolero was equal to or better than that obtained through weekly fungicide applications.

Program active ingredient and toxicity. Total fungicide inputs and toxicity units needed to manage ALB and CLS were reduced using weather-based spray programs without significantly compromising disease control. Compared with a weekly spray program, weather-based spray programs reduced the total active ingredient (a.i.) by 2.77 to $4.24 \mathrm{lb}$ a.i./ha using a 20 DSV threshold with Bolero, and by 2.14 to $2.98 \mathrm{lb}$ a.i./ha using a $15 \mathrm{DSV}$ threshold with Fontana. An alternation program of chlorothalonil and azoxystrobin for ALB and CLS resulted in a substantial reduction in toxicity units over the Wisconsin industry standard program which usually consists of an average of seven sprays of only chlorothalonil (Fig. 2 ). Total toxicity units were reduced on Bolero by 498 units in 2002 and 746 units in 2003 and 2004 for the 20 DSV spray program compared with the weekly spray program. On Fontana, total toxicity units were decreased by 270 units in 2002 and 506 units in 2003 and 2004 for the 15 DSV spray program compared with the weekly spray program.

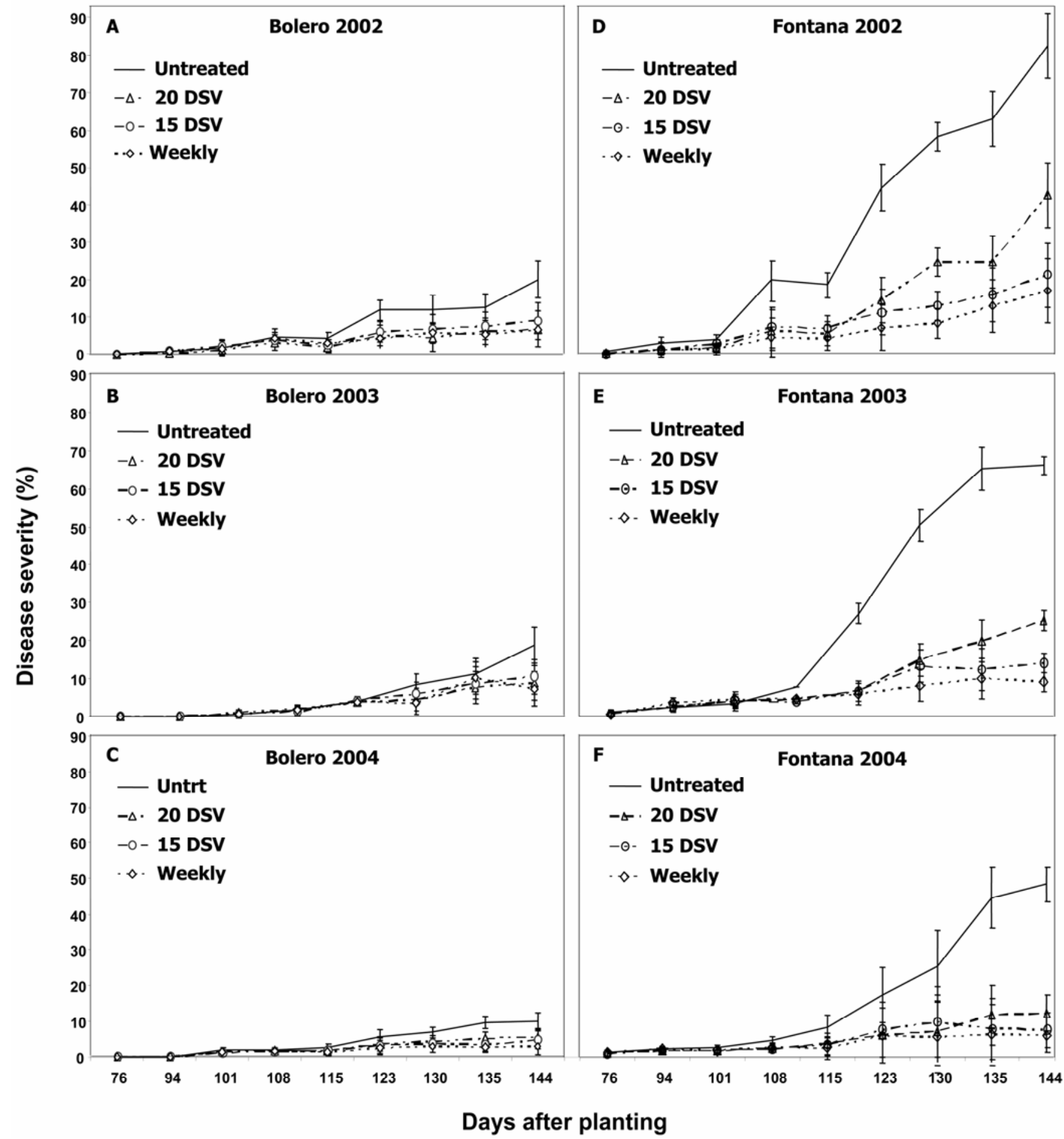

Fig. 1. Disease severity (\%) and progression of Alternaria leaf blight and Cercospora leaf spot on carrots treated with fungicide weekly, according to 15 or 20 disease severity value (DSV) schedules and untreated during 2002 to 2004. Data are presented for each cultivar in each year of the study. 


\section{DISCUSSION}

Vegetable growers and processors in Wisconsin and other states in the Midwest are interested in reducing pesticide inputs and the possible deleterious impact of production practices on their land. Carrot producers would like to offset their reliance on fungicides for disease control by incorporating alternative and cost effective techniques for ALB and CLS control. The combination of weather-based fungicide spray programs with disease scouting, disease monitoring, and cultivar resistance demonstrate potential to diminish industry dependence solely on repeated applications of chlorothalonil.

As demonstrated in this 3-year study, weather-based fungicide spray schedules offer an effective means for carrot growers to reduce the number of fungicide sprays required for control of ALB and CLS compared with the standard, weekly, calendar-based spray programs. Both 15 and 20 DSV TOM-CAST spray programs provided foliar disease control equivalent to the weekly spray program on the resistant cultivar Bolero, with fewer indicated fungicide applications. Similarly, for the susceptible cultivar Fontana, disease control with four to five sprays based on the 15 DSV spray program was comparable to eight sprays using the weekly program. It appears that adequate or even improved carrot yields may be achieved with fewer fungicide sprays than the current commercial management program used in Wisconsin, by incorporating a disease forecasting model such as TOM-CAST.

Disease severity values accumulated at an accelerated rate in 2002 compared with 2003 or 2004, resulting in shorter spray intervals for the weather-based spray programs. Weather patterns in 2002 favored development of ALB and CLS, as mild temperatures accompanied repeated periods of leaf wetness resulting from frequent evening dews. As a result, disease severity during 2002 increased steadily through September, even in plots treated with fungicide. In 2003, August was relatively dry in central Wisconsin, with only $2.41 \mathrm{~cm}$ of precipitation. Evenings in August 2004 were typically cooler than normal (average of 2.8 and $4.5^{\circ} \mathrm{C}$ cooler than in 2003 and 2002, respectively). Evening dews were less frequent in 2003 and 2004, resulting in shortened durations of leaf wetness. This contributed to slower disease progress and DSV accumulation in 2003 and 2004, resulting in one less fungicide spray for both weather-based programs in these years compared with 2002. These results confirm the value of using weather-based fungicide spray programs in carrot crops under different annual environmental conditions.

Differences in host susceptibility among the two cultivars examined in this study played an important role in the overall management of ALB and CLS and the effectiveness of each weather-based spray program interval (15 or 20 DSV). Fontana required earlier and more thorough scouting to determine initial disease onset, and a greater number of fungicide sprays for the weekly and 15 DSV spray programs to achieve adequate suppression of ALB and CLS compared with a 20 DSV program on Bolero. In all 3 years of the experiment, disease was observed later in Bolero plots and symptom severity progressed more slowly than in plots of Fontana. The size and rate of expansion of ALB and CLS lesions appear to be limited on Bolero when compared with Fontana, resulting in less disease being observed in the untreated Bolero plots compared with Fontana plots that received four or five fungicide sprays. In addition, effects of planting density on the microclimate within the canopy were not observed, even though the resistant cultivar Bolero was planted at twice the density of Fontana.

Impact of ALB and CLS on total yield was likely underestimated in this study because carrots were hand-harvested. Plots of the susceptible cultivar Fontana, especially those receiving no fungicide, had brittle and blighted foliage by harvest in each year. Under these circumstances, petioles may have broken off if mechanically harvested, resulting in even lower yields. Root quality, root diameter, and total yield were similar among all fungicide-treated plots regardless of cultivar. However, plots receiving no fungicide

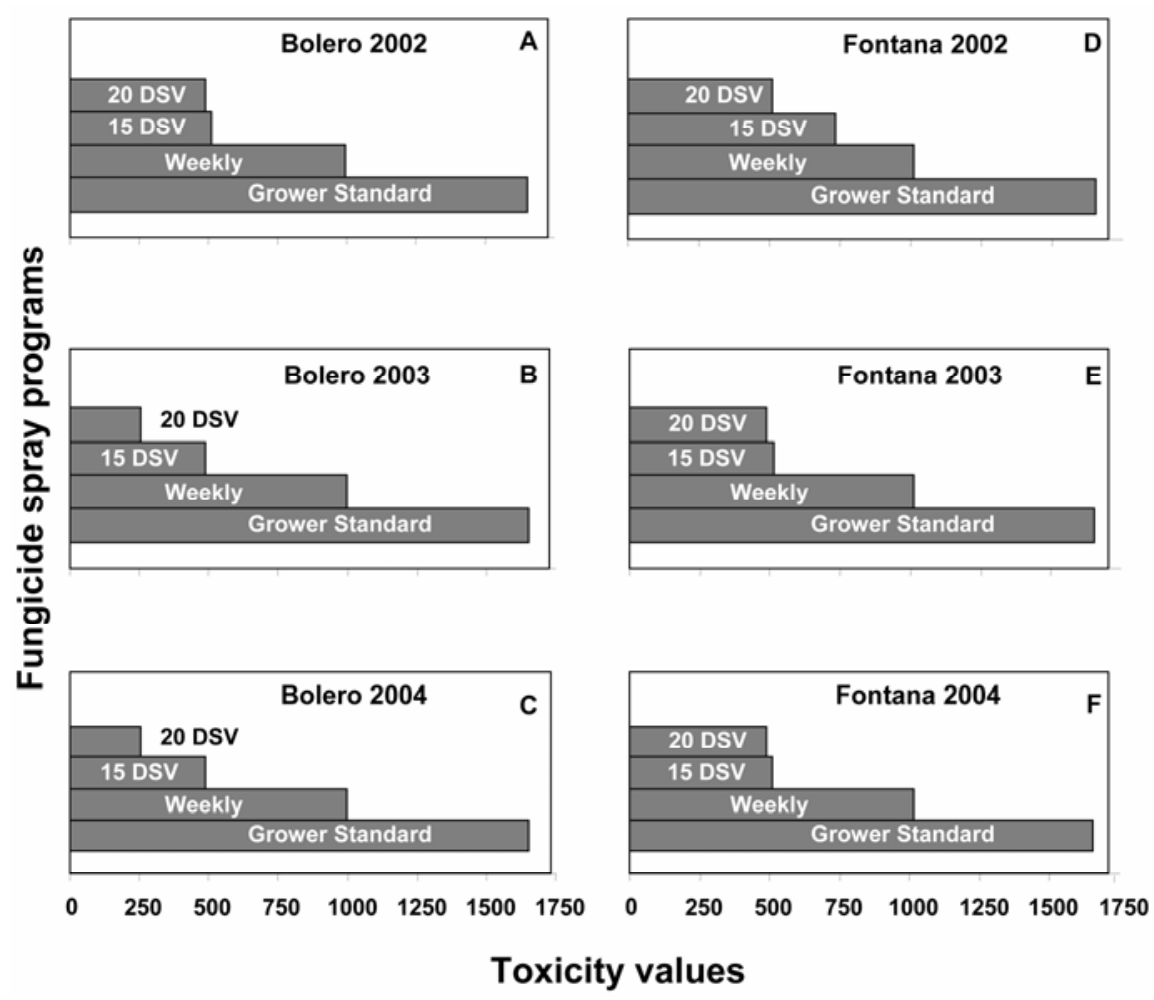

Fig. 2. Comparative toxicity values (2) per hectare for fungicide spray programs applied weekly or according to 15 or 20 disease severity value (DSV) intervals to control Alternaria leaf blight and Cercospora leaf spot. The "Grower Standard" program, consisting of seven sprays of chlorothalonil alone, was not included in this experiment. It represents a fungicide program used by most Wisconsin carrot growers during 2002 to 2004. displayed smaller diameter, lower quality roots (stubby, short, and misshapen). As a result, small diameter roots from severely diseased plants in this trial reduced overall crop value, especially on the cultivar Fontana.

Accurate timing of the initial fungicide spray is an important requirement for successful chemical control of ALB and CLS without the addition of unwarranted applications $(1,4,5,14)$. Currently, growers in Wisconsin apply fungicides when plants reach a particular plant growth stage (e.g., height of $20 \mathrm{~cm})$. Often, inoculum availability and environmental conditions within the plant canopy are not factored into these strategies, resulting in fungicides being applied earlier than necessary. Applying fungicides when disease symptoms are first detected may reduce early-season fungicide applications by eliminating unwarranted sprays. This research and related studies in Canada suggest effective control of ALB and CLS can be accomplished, whether a disease incidence threshold (e.g., 25 or $50 \%$ of the middle leaves showing symptoms) or a $1 \%$ severity threshold is employed, when initial applications are made immediately after disease onset $(1,5,14,20)$. Furthermore, this technique provided greater benefit on resistant cultivar Bolero, as the initial fungicide application was delayed by 12 to 19 days over all 3 years compared with susceptible cultivar Fontana.

Plant Disease / March 2006 
Current management strategies for ALB and CLS in Wisconsin rely almost exclusively on the pesticide chlorothalonil, because of its efficacy and reduced cost compared with other labeled products (unpublished grower survey). Midwest processors are interested in a reduced-risk (e.g., low impact on human health, low potential for groundwater contamination, and lower use rate) fungicide program that incorporates novel effective chemistries that reduce the amount of active ingredient applied to vegetable crops. Weather-based spray programs in this experiment demonstrated equivalent disease control to a calendar program with less active ingredient and fewer total toxicity values. Alternating azoxystrobin and chlorothalonil on a weather-based spray schedule reduced the amount of active ingredient and total toxicity values by 55 to $80 \%$ (15 DSV) and 55 to $85 \%$ (20 DSV), when compared with the industry standard fungicide program of seven sprays of chlorothalonil (Bravo Ultrex at $1.57 \mathrm{~kg} / \mathrm{ha}$, which results in $9.1 \mathrm{~kg}$ a.i./ha and 1,652.7 toxicity units).

The TOM-CAST model accounted for changes in annual weather conditions and subsequent disease pressure, indicating fewer sprays were needed in 2003 and 2004 (drier or cooler, less favorable years for ALB and CLS) than in 2002. Results of this experiment concur with other similar studies on control of early blight (A. solani) on tomato and late blight ( $P$. infestans) on potato $(12,15,22,24)$. In these studies, fewer applied sprays based upon a forecasting model provided adequate, if not superior, disease control compared with calendar-based programs. Furthermore, this study and the above-mentioned research demonstrated the additional benefits of incorporating disease resistance into fungicide spray programs, requiring less fungicide than standard susceptible cultivars.

Carrot foliar disease management programs that incorporate weather conditions and cultivar susceptibility offer growers a means to improve disease control while diminishing reliance on weekly applications of chlorothalonil and an opportunity to reduce costs associated with disease management. Integration of weather-timed sprays with host resistance and disease monitoring is being examined in a side-byside comparison with standard fungicide programs in large-scale field trials in commercial production fields in Wisconsin.

\section{ACKNOWLEDGMENTS}

We thank the UW College of Agriculture and Life Sciences, Wisconsin Carrot Growers, Mary
Hausbeck, Michigan State University, UWHancock Agricultural Research Station staff, and funding sources-USDA-RAMP, EPA, Midwest Food Processors Association, and American Farmland Trust-for all their efforts in this research project.

\section{LITERATURE CITED}

1. Abraham, V., Kushalappa, A. C., Carisse, O., Bourgeois, G., and Auclair, P. 1995. Comparison of decision methods to initiate fungicide applications against Cercospora blight of carrot. Phytoprotection 76:91-99.

2. Benbrook, C. A., Sexson, D. L., Wyman, J. A., Stevenson, W. R., Lynch, S., Wallendal, S., Diercks, J., VanHaren, R., and Granadino, C. A. 2002. Monitoring progress on reducing reliance on high-risk pesticides in WI potato production. Am. J. Pot. Res. 79:183-199.

3. Ben-Noon, E., Shtienberg, D., Shelvin, E., Vintal, H., and Dinoor, A. 2001. Optimization of chemical suppression of Alternaria dauci the causal agent of Alternaria blight in carrots. Phytopathology 67:1262-1266.

4. Bounds, R. S. 2003. Using scouting and disease forecasters to manage foliar blights of carrots. M.S. thesis. Michigan State University, East Lansing.

5. Carisse, O., and Kushalappa, A. C. 1990. Development of an infection model for Cercospora carotae on carrot based on temperature and leaf wetness duration. Phytopathology 80:1233-1238.

6. Carisse, O., Kushalappa, A. C., and Cloutier, D. C. 1993. Influence of temperature, leaf wetness, and high relative humidity duration on sporulation of Cercospora carotae on carrot leaves. Phytopathology 83:338-343.

7. Doran, W. L., and Guba, E. F. 1928. Blight and leaf spot of carrot in Massachusetts. Mass. Agric. Exp. Stn. Bull. 245:271-278.

8. Dugdale, L. J., Mortimer, A. M., Isaac, S., and Collin, H. A. 2000. Disease response of carrot and carrot somaclones to Alternaria dauci. Plant Pathol. 49:57-67.

9. Fry, W. E. 1977. Integrated control of potato late blight. Effects of polygenic resistance and techniques of timing fungicide applications. Phytopathology 67:415-420.

10. Fry, W. E. 1978. Quantification of general resistance of potato cultivars and fungicide effects for integrated control of potato late blight. Phytopathology 68:1650-1655.

11. Fry, W. E., Apple, A. E., and Bruhn, J. A. 1983. Evaluation of potato late blight forecasts modified to incorporate host resistance and fungicide weathering Phytophthora infestans, Solanum tuberosum. Phytopathology 73:10541059.

12. Fry, W. E., and Shtienberg, D. 1990. Integration of host resistance and fungicide to manage potato diseases. Can. J. Plant Pathol. 12:111116.

13. Gillespie, T. J., Srivastava, B., and Pitbaldo, R. E. 1993. Using operational weather data to schedule fungicide sprays on tomatoes in southern Ontario, Canada. J. Appl. Meteorol. 32:567-573.

14. Gillespie, T. J., and Sutton, J. C. 1979. A predictive scheme for timing fungicide applications to control Alternaria leaf blight in carrots. Can. J. Plant Pathol. 1:95-99.

15. Grunwald, N. J., Rubio-Covarrubias, O. A., and Fry, W. E. 2000. Potato late-blight man- agement in the Toluca Valley: Forecasts and resistant cultivars. Plant Dis. 84:410-416.

16. Hooker, W. J. 1944. Comparative study of two carrot leaf diseases. Phytopathology 34:606612.

17. Horsfall, J. G., and Barratt, R. W. 1945. An improved grading system for measuring plant diseases. Phytopathology 35:655.

18. James, R. V., Stevenson, W. R., and Rand, R. 2001. Evaluation of carrot cultivars and breeding selections to identify resistance to foliar blights 2000. Biol. Cultural Tests 16:V83.

19. James, R. V., Stevenson, W. R., and Rand, R. 2001. Evaluation of fungicides to control carrot foliar blights. 2000. Fungic. Nematicide Tests 56:V6.

20. Kushalappa, A. C., Boivin, G., and Brodeur, L. 1989. Forecasting incidence thresholds of Cercospora blight of carrots to initiate fungicide application. Plant Dis. 73:979-983.

21. Krause, R. A., Massie, L. B., and Hyre, R. A. 1975. BLITECAST: A computerized forecast of potato late blight. Plant Dis. Rep. 59:95-98.

22. Langenberg, W. J., Sutton, J. C., and Gillespie, T. J. 1977. Relation of weather variables and periodicities of airborne spores of Alternaria dauci. Phytopathology 67:879-883.

23. Lebeda, A., Coufal, J., and Kvasnicka, P. 1988. Evaluation of field resistance of Daucus carota cultivars to Cercospora carotae (carrot leaf spot). Euphytica 39:285-288.

24. Madden, L. V., Pennypacker, S. P., and MacNab, A. A. 1978. FAST, a forecasting system for Alternaria solani on tomato. Phytopathology 68:1354-1358.

25. Pitblado, R. 1992. The development and implementation of TOM-CAST. Ontario Ministry of Agriculture and Food. p. 18

26. Pryor, B. M., and Strandberg, J. O. 2001 Alternaria leaf blight of carrot and Cercospora leaf blight of carrot. Pages 1-19 in: Compendium of Umbelliferous Crop Diseases. R. M Davis and R. N. Raid, eds. American Phytopathological Society, St. Paul, MN.

27. Pryor, B. M., Strandberg, J. O., Davis, R. M., Nunez, J. J., and Gilbertson, R. L. 2001. Survival and persistence of Alternaria dauci in carrot cropping systems. Plant Dis. 86:11151122

28. Rogers, P. M., Stevenson, W. R., James, R. V., and Rand, R. 2002. Evaluation of carrot cultivars and breeding selections to identify resistance to foliar blights. Lewiston and Hancock. 2001. Biol. Cultural Tests 17:VD8-VD9.

29. Rotem, J. 1994. The Genus Alternaria. Biology, Epidemiology, and Pathogenecity. American Phytopathological Society, St. Paul, MN

30. Shtienberg, D., Raposo, R., Bergeron, S. N., Legard, D. E., Dyer, A. T., and Fry, W. E. 1994. Incorporation of cultivar resistance in a reduced-sprays strategy to suppress early and late blights on potato. Plant Dis. 78:23-26.

31. Strandberg, J. O. 1977. Spore production and dispersal of Alternaria dauci. Phytopathology 67:1262-1266.

32. Strandberg, J. O. 1988. Establishment of Alternaria leaf blight on carrots in controlled environments. Plant Dis. 72:522-526.

33. Strider, D. L. 1963. Control of Alternaria blight of carrot. Plant Dis. Rep. 47:68-69.

34. Sutton, J. C., and Gillespie, T. J. 1979. Weather-timed sprays for carrot blight control. Fact Sheet Ontario Ministry of Agriculture and Food, AGDEX 258/635. 